\title{
PENERAPAN METODE AHP (ANALYTIC HIERARCHY PROCESS) DALAM PEMILIHAN BIBIT UNGGUL BUAH PEPAYA MENGGUNAKAN BAHASA PEMOGRAMAN PHP DAN DATABASE MYSQL
}

\author{
Dinul Akhiyar ${ }^{1}$, Irzal Arief Wisky², Radiyan Rahim ${ }^{3}$ \\ ${ }^{1}$ Sistem Informasi, Universitas Putra Indonesia "YPTK" Padang \\ 2 Sistem Informasi, Universitas Putra Indonesia "YPTK" Padang \\ ${ }^{3}$ Sistem Informasi, Universitas Pembangunan Panca Budi \\ E-mail : dinul_akhiyar@ymail.com \\ E-mail : irzal.arief12@gmail.com \\ E-mail : radiyanrahim@gmail.com
}

\begin{abstract}
Abstrak
Sistem yang akan dibuat dalam untukpengambilan keputusan ini adalah dengan menggunakan metode AHP (Analytic Hierarchy Process). Metode AHPAdalah metode untuk memecahkan suatu situasi yang komplek tidak terstruktur kedalam beberapa komponen dalam susunan yang hirarki, dengan memberi nilai subjektif tentang pentingnya setiap variabel secara relatif, Pemilihan bibit Pepaya biasanya berdasarkan berbagai macam keinginan tidak hanya melihat dari segi financial saja akan tetapi dari berbagai kriteria lain seperti rasa, warna ,kandungan air, harga, cepat pertumbuhan, usia pohon dan lama panen, dengan menerapkan pemrograman PHP dan database MySQL.
\end{abstract}

Kata kunci: AHP, Mysql, Pemrograman.

\section{Pendahuluan}

\subsection{Latar Belakang Masalah}

Buah Pepaya (Caraca Pepaya) atau Betik merupakan salah satu jenis tumbuhan dari genus Carica yang sangat bermanfaat. Dari tumbuhan ini dapat diambil buah, biji, getah, dan daunnya kemudian dimanfaatkan dan digunakan dalam kehidupan sehari-hari.Melihat banyak manfaatnya tumbuhan Buah Pepaya di masa ini dan masa yang akan datang, maka perlu dipikirkan usaha peningkatan kualitas Pepaya secara tepat agar sasaran yang diinginkan dapat tercapai. Pertumbuhan awal bibit merupakan periode kritis yang sangat menentukan keberhasilan tanaman dalam mencapai pertumbuhan yang baik, dipembibitan pertumbuhan dan figur bibit sangat ditentukan oleh kecambah yang ditanam.

Dengan adanya sistem pendukung keputusan dapat meningkatkan kualitas sistem pendukung keputusan yang akan dibuat. Sebagai contoh, dalam pemilihan bibit Pepaya yang berkualitas baik yang digunakan untuk proses penanaman Buah Pepaya dilahan baru. Pemilihan bibit Pepaya biasanya berdasarkan berbagai macam keinginan tidak hanya melihat dari segi financial saja akan tetapi dari berbagai kriteria lain seperti rasa, warna ,kandungan air, harga, cepat pertumbuhan, usia pohon dan lama panen.

Jika saja bibit pepaya yang akan dipilih sudah sesuai dengan keinginan, maka sudah tentu bibit pepaya tersebut akan menjadi factor pendukung yang baik. Sistem yang akan dibuat dalam untukpengambilan keputusan ini adalah dengan menggunakan metode AHP (Analytic Hierarchy Process). Metode AHPAdalah metode untuk memecahkan suatu situasi yang komplek tidak terstruktur kedalam beberapa komponen dalam susunan yang hirarki, dengan memberi nilai subjektif tentang pentingnya setiap variabel secara relatif.

$\begin{array}{ll}\text { Dikirim } & : 2018-11-15 \\ \text { Diterima } & : 2018-12-10 \\ \text { Diterbitkan } & : 2018-12-13\end{array}$


Berdasarkan latar belakang permasalahan tersebut maka dalam penelitian ini akan dibuat sebuah "PENERAPAN METODE AHP(Analytic Hierarchy Process) DALAM PEMILIHAN BIBIT UNGgUL BUAH PEPAYA (Studi Kasus Petanian Buah Tropika) MENGGUNAKAN BAHASA PEMOGRAMAN PHP DAN DATABASE MySQL".

\subsection{Perumusan Masalah} berikut :

Adapun beberapa permasalahan yang akan dibahas dalam penelitian ini adalah sebagai

1. Bagaimana cara menentukan kriteria sistem pendukung keputusan dalam memilih bibit buah pepay yang akan ditanam ?

2. Bagaimana menghitung matriks kriteria dan subkriteria dalam metode Analitical Hirarcy Process pada sistem pendukung keputusan pemilihan bibit buah pepaya?

\subsection{Hipotesa}

Berdasarkan perumusan masalah dapat disimpulkan beberapa hipotesa sebagai berikut :

1. Diharapkan dengan menggunakan sistem pendukung keputasan ini dapat menentukan kriteria apa saja yang diperlukan untuk menghasilkan kualitas bibit buah pepaya terbaik.

2. Diharapkan dengan penelitian ini penulis dapat mengitung hasil kriteria dan subkriteria dengan menerapkan metode AHP dalam pendukung keputusan pemilihan kualitas bibit buah pepaya.

3. Diharapkan dengan sistem informasi pendukung keputusan yang akan dibangun dapat membantu asisten dilapangan menentukan kualitas bibit buah pepaya berkualitas.

\section{Landasan Teori}

\subsection{Konsep Dasar Sistem Pendukung Keputusan}

\subsubsection{Definisi sistem}

Menurut Tata Sutabri dalam bukunya berjudul "konsep sistem informasi" Sistem pada dasarnya adalah sekelompok unsur yang erat hubungannya satu dengan yang lain yang berfungsi bersama-sama untuk mencapai tujuan tertentu. Terdapat dua kelompok pendekatan di dalam mendefinisikan sistem, yaitu yang menekankan pada prosedurnya dan menekankan pada komponen atau elemennya

1. Pendekatan sistem yang menekan pada prosedur

Mendefenisikan sistem sebagai suatu jaringan kerja dari prosedur prosedur yang saling berhubungan. (Tata Sutabri, 2012).

2. Pendekatan yang menekankan pada elemen atau komponennya

Mendefenisikan sistem sebagai kumpulan dari elemen-elemen yang berinteraksi untuk mencapai suatu tujuan. (Tata Sutabri, 2012) ${ }^{[1]}$.

\subsubsection{Pendukung Keputusan}

Keputusan merupakan kegiatan memilih suatu strategi atau tindakan dalampemecahan masalah tersebut.Tindakan memilih strategi atau aksi yang diyakini manajerakan memberikan solusi terbaik atas sesuatu itu disebut pengambilan keputusan

\subsubsection{Metode AHP (Analytic Hierarchy Process)}

\subsubsection{Pengertian AHP}

AHP (Analytic Hierarchy Process) adalah suatu teori umum tentang pengukuran yang digunakan untukmenemukan skala rasio, baik dari perbandingan berpasangan yang diskrit maupun kontinyu. AHP menguraikan masalah multi faktor atau multi kriteria yang kompleks menjadi suatu hirarki. Hirarki didefinisikan sebagai suaturepresentasi dari sebuah permasalahan 
yang kompleks dalam suatu struktur multi level dimana level pertama adalah tujuan, yang diikuti level faktor, kriteria, sub kriteria, dan seterusnya ke bawah hingga level terakhir dari alternatif .Dengan hirarki, suatu masalah yang kompleks dapat diuraikan ke dalam kelompokkelompoknya yang kemudiandiatur menjadi suatu bentuk hirarki sehingga permasalahan akan tampak lebih terstruktur dan sistematis (Eko darmanto, Noor latifah, Nanik Susanti, 2014: 77). Kelebihan dari AHP adalah karena pembuat keputusan tidak perlu menentukan bobot pasti tiap kriteria.

Tahapan - tahapan pengambilan keputusan dalam metode AHP pada dasarnya adalah sebagai berikut :

a. Mendefinisikan masalah dan menentukan solusi yang diinginkan

b. Membuat struktur hirarki yang diawali dengan tujuan umum, dilanjutkan dengan kriteriakriteria dan alternaif-alternatif pilihan yang ingin dirangking.

c. Membentuk matriks perbandingan berpasangan yang menggambarkan kontribusi relatif atau pengaruh setiap elemen terhadap masing-masing tujuan atau kriteria yang setingkat diatasnya. Perbandingan dilakukan berdasarkan pilihan atau judgement dari pembuat keputusan dengan menilai tingkat tingkat kepentingan suatu elemen dibandingkan elemen lainnya

d. Menormalkan data yaitu dengan membagi nilai dari setiap elemen di dalam matriks yang berpasangan dengan nilai total dari setiap kolom.

e. Menghitung nilai eigen vector dan menguji konsistensinya, jika tidak konsisten maka pengambilan data (preferensi) perlu diulangi. Nilai eigen vector yang dimaksud adalah nilai eigen vector maximum yang diperoleh dengan menggunakan matlab maupun dengan manual.

f. Mengulangi langkah 3, 4, dan 5 untuk seluruh tingkat hirarki.

g. Menghitung eigen vector dari setiap matriks perbandingan berpasangan. Nilai eigen vector merupakan bobot setiap elemen. Langkah ini untuk mensintesis pilihan dalam penentuan prioritas elemen-elemen pada tingkat hirarki terendah sampai pencapaian tujuan.

h. Menguji konsistensi hirarki. Jika tidak memenuhi dengan $\mathrm{CR}<0,100$ maka penilaian harus diulang kembali.

\subsubsection{Prinsip Dasar Analytic Hierarchy Process (AHP)}

Dalam menyelesaikan persoalan dengan metode AHP ada beberapa prinsip dasar yang harusdipahami antaralain :

1. Decomposition adalah memecahkan atau membagi problema yang utuh menjadi unsur unsurnya ke bentuk hirarki proses pengambilan keputusan, dimana setiap unsur atau elemen saling berhubungan. Struktur hirarki keputusan tersebut dapat dikategorikan sebagai complete dan incomplete. Suatu hirarki keputusan disebut complete jika semua elemen pada suatu tingkat memiliki hubungan terhadap semua elemen yang ada pada tingkat berikutnya, sementara hirarki keputusan incomplete kebalikan dari hirarki yang complete. Bentuk struktur dekomposisi yakni

Tingkat pertama :Tujuan keputusan(Goal)

Tingkat kedua :Kriteria - kriteria

Tingkat ketiga :Alternatif-alternatif 


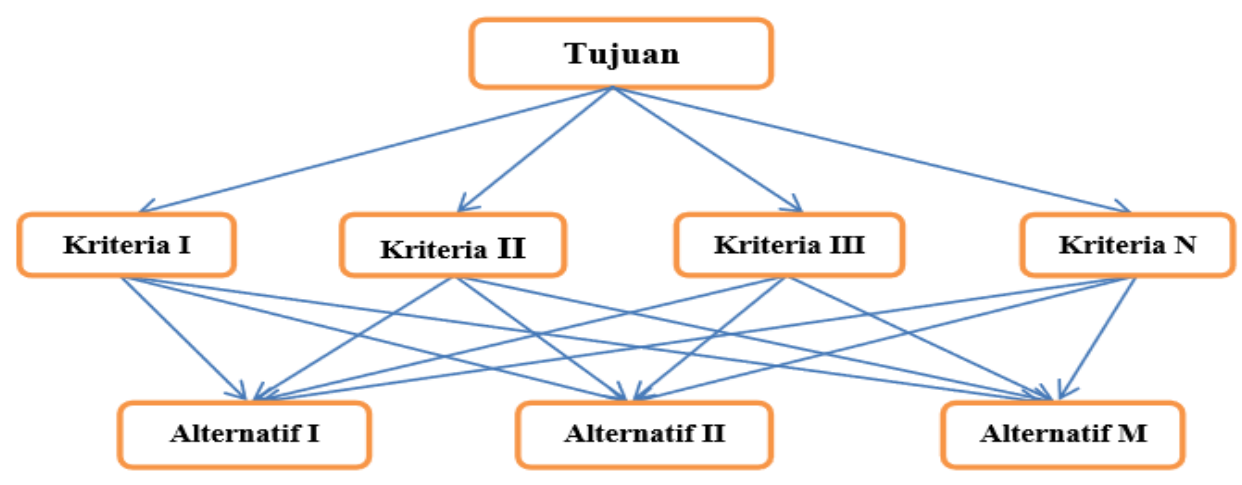

Gambar 2.5.2 Struktur Hirarki

Hirarki masalah disusun digunakan untuk membantu proses pengambilan keputusan dalam sebuah sistem dengan memperhatikan seluruh elemen keputusan yang terlibat.

2. Comparative Judgement merupakan inti dari penggunaan AHP karena akan berpengaruh terhadap urutan prioritas dari elemen-elemennya. Hasil dari penilaian tersebut akan diperlihatkan dalam bentuk matriks pairwise comparisons yaitu matriks perbandingan berpasangan memuat tingkat preferensi beberapa alternatif untuk tiap kriteria. Skala preferensi yang digunakan yaitu skala 1 yang menunjukkkan tingkat yang paling rendah (equal importance) sampai dengan skala 9 yang menunjukkan tingkatan yang paling tinggi (extreme importance).

3. Synthesis of Priority dilakukan dengan menggunakan eigen vektor method untuk mendapatkan bobot relatif bagi unsur-unsur pengambilan keputusan.

4. Logical Consistency dilakukan dengan mengagresikan seluruh eigen vektor yang diperoleh dari berbagai tingkatan hirarki dan selanjutnya.

a. Penyusunan prioritas

Setiap elemen yang terdapat dalam hirarki harus diketahui bobot relatifnya satu sama lain. Tujuannya adalah untuk mengetahui tingkat kepentingan pihak - pihak yang berkepentingan dalam permasalahan terhadap kriteria dan struktur hirarki atau sistem secara keseluruhan.

Langkah awal dalam menentukan prioritas kriteria adalah dengan menyusun perbandingan berpasangan, yaitu membandingkan dalam bentuk berpasangan seluruh kriteria untuk setiap sub sistem hirarki. Perbandingan tersebut kemudian ditransformasikan dalam bentuk matriks perbandingan berpasangan untuk analisis numerik. Misalkan terdapat sub sistem hirarki dengan kriteria $\mathrm{C}$ dan sejumlah $\mathrm{n}$ alternatif dibawahnya, Ai sampai An. Perbandingan antar alternatif untuk sub sistem hirarki itu dapat dibuat dalam bentuk matriks $n \times n$, seperti pada tabel A1 dibawah ini.

$\begin{array}{lllll}\text { C } & \text { A1 } & \text { A2 } & \ldots & \text { An } \\ \text { A1 } & \text { a11 } & \text { a12 } & \ldots & \text { a1n } \\ \text { A2 } & \text { a21 } & \text { a22 } & \ldots & \text { a2n } \\ \ldots & \ldots & \ldots & \ldots & \\ \text { Am } & \text { Aml } & \text { am2 } & \ldots & \text { Amn }\end{array}$

Nilai a11, a22,... amn adalah nilai perbandingan elemen baris Al terhadap kolom Al yang menyatakan hubungan:

1. Seberapa jauh tingkat kepentingan baris A terhadap kriteria $\mathrm{C}$ dibandingkan dengan kolom Al19

2. Seberapa jauh dominasi baris $\mathrm{Al}$ terhadap kolom $\mathrm{Al}$ atau 
3. Seberapa banyak sifat kriteria $\mathrm{C}$ terdapat pada baris $\mathrm{Al}$ dibandingkan dengan kolom Al.

Nilai numerik yang dikenakan untuk seluruh perbandingan diperoleh dari skala perbandingan 1 sampai 9 yang telah ditetapkan oleh Saaty, seperti pada tabel A.2 berikut ini.

\begin{tabular}{|c|c|l|}
\hline $\begin{array}{c}\text { Tingkat } \\
\text { Kepentingan }\end{array}$ & Defenisi & \multicolumn{1}{|c|}{ Keterangan } \\
\hline 1 & $\begin{array}{c}\text { Sama } \\
\text { Pentingnya }\end{array}$ & $\begin{array}{l}\text { Kedua elemen mempunyai pengaruh yang } \\
\text { sama }\end{array}$ \\
\hline 3 & $\begin{array}{c}\text { Sedikit Lebih } \\
\text { Penting }\end{array}$ & $\begin{array}{l}\text { Pengalaman dan penilaian sangat memihak } \\
\text { satu elemen dibandingkan dengan } \\
\text { pasangannya }\end{array}$ \\
\hline 5 & Lebih Penting & $\begin{array}{l}\text { Satu elemen sangat disukai dan secara praktis } \\
\text { dominasinya sangat nyata, dibandingkan } \\
\text { dengan elemen pasangannya }\end{array}$ \\
\hline 7 & Sangat Penting & $\begin{array}{l}\text { Satu elemen terbukti sangat disukai dan secara } \\
\text { praktis dominasinya sangat nyata, dibandigkan } \\
\text { dengan elemen pasangannya }\end{array}$ \\
\hline 5,6 & Nilai Tengah & $\begin{array}{l}\text { Satu elemen terbukti mutlak lebih disukai } \\
\text { diantara dua tingkat kepentingan yang } \\
\text { berdekatan }\end{array}$ \\
\hline & dibandigkan dengan pasangannya, pada \\
& keyakinan tertinggi \\
\hline
\end{tabular}

Skala Penilaian Perbandingan Berpasangan

Matriks berpasangan pada setiap level hirarki. Contoh Pair-Wise Comparison Matrix pada suatu level of hierarchy, yaitu:

Contoh Matriks Perbandingan Berpasangan D

$\begin{array}{lllll} & \mathrm{D} & \mathrm{E} & \mathrm{F} & \mathrm{G} \\ \mathrm{D} & 1 & 3 & 7 & 9 \\ \mathrm{E} & 1 / 3 & 1 & 1 / 4 & 1 / 8 \\ \mathrm{~F} & 1 / 7 & 4 & 1 & 5 \\ \mathrm{G} & 1 / 9 & 8 & 1 / 5 & 1\end{array}$

2. Eigen value dan eigen vector

Untuk melengkapi pembahasan tentang eigen value dan eigen vector maka akan diberikan definisi - definisi mengenai matriks dan vector.

1. Matriks

Matriks merupakan sekumpulan himpunan objek (bilangan riil atau kompleks, variabel - variabel) yang terdiri dari baris dan kolom dan di susun persegi panjang. Matriks biasanya terdiri dari $\mathrm{m}$ baris dan $n$ kolom maka matriks tersebut berukuran (ordo) $\mathrm{m} \times \mathrm{n}$. Matriks dikatakan bujur sangkar (square matrix) jika $\mathrm{m}$ $=n$. Dan skalar - skalarnya berada di baris ke-i dan kolom ke-j yang disebut (ij) matriks entri.

2. Vektor dari $n$ dimensi

Suatu vektor dengan $n$ dimensi merupakan suatu susunan elemen - elemen yang teratur berupa angka - angka sebanyak $n$ buah, yang disusun baik menurut baris, dari kiri ke kanan (disebut vector baris atau Row Vektor dengan ordo $1 \times n$ ) maupun menurut kolom, dari ataske bawah (disebut vector kolom atau Colomn 
Vector dengan ordo $n \mathrm{x} 1$ ). Himpunan semua vector dengan $n$ komponen dengan entri riil dinotasikan dengan R'. 22

3. Prioritas, Eigen value dan eigen vector

Untuk menentukan nilai dari masing masing pada matrik $\mathrm{m} \times \mathrm{n}$ maka; Nilai total matriks dalam masing-masing kolom di bandingkan dengan nilai matriks dan dijumlahkan untuk tiap baris. Total nilai baris dari matrik hasil perhitungan tersebut dijumlahkan. Untuk mementukan nilai prioritas adalah dengan membandingkan nilai total baris dalam matrik tersebut dengan nilai total dari kolom hasil perhitungan tersebut. Nilai eigen value di dapatkan dari total jumlah dari perkalian nilai prioritas dalam matrik dibandingkan dengan nilai prioritas tersebut. Nilai eigen value merupakan total dari nilai eigen dibagi dengan ordo matriks atau $n$.

3.Uji konsistensi indeks dan rasio

Hal yang membedakan AHP dengan model—model pengambilan keputusan yang lainnya adalah tidak adanya syarat konsistensi mutlak. Model AHP yang memakai persepsi decision maker sebagai inputnya maka ketidakkonsistenan mungkin terjadi karena manusia memiliki keterbatasan dalam menyatakan persepsinya secara konsisten terutama kalau harus mambandingkan banyak kriteria.

\section{Analisa dan Perancangan}

\subsection{Perancangan Sistem Dengan Menggunakan UML}

Unfied Modelling Language (UML) adalah sebuah "bahasa" yang telah menjadi standar dalam industri untuk visualisasi, merancang dan mendokumentasikan sistem perangkat lunak, alat bantu berupa Unified Modelling Language (UML) agar mempermudah memindahkan konsep sistem yang dirancang ke dalam bentuk program, dimana perancangannya digambarkan dalam bentuk diagram-diagram berikut :

\section{Implementasi sistem}

\subsection{Implementasi sistem}

Implementasi sistem adalah sistem yang siap pakai untuk diterapkan pada sebuah perusahaan yang telah diteliti. Sebelum diimplementasikan secara langsung pada perusahaan, perlu dilakukan pengujian terlebih dahulu.

\subsection{Pengujian Sistem}

Pada pengujian sistem ini akan menampilkan sistem dan cara kerja sistem. Pada saat program dijalankan.

1. Halaman Awal Website.

Halaman awal website merupakan halaman yang akan ditampilkan ketika pertama kali membuka sistem aplikasi pengambilan keputusan ini. Halaman website ini berisikan form login yang akan digunakan oleh administaror dan user. 


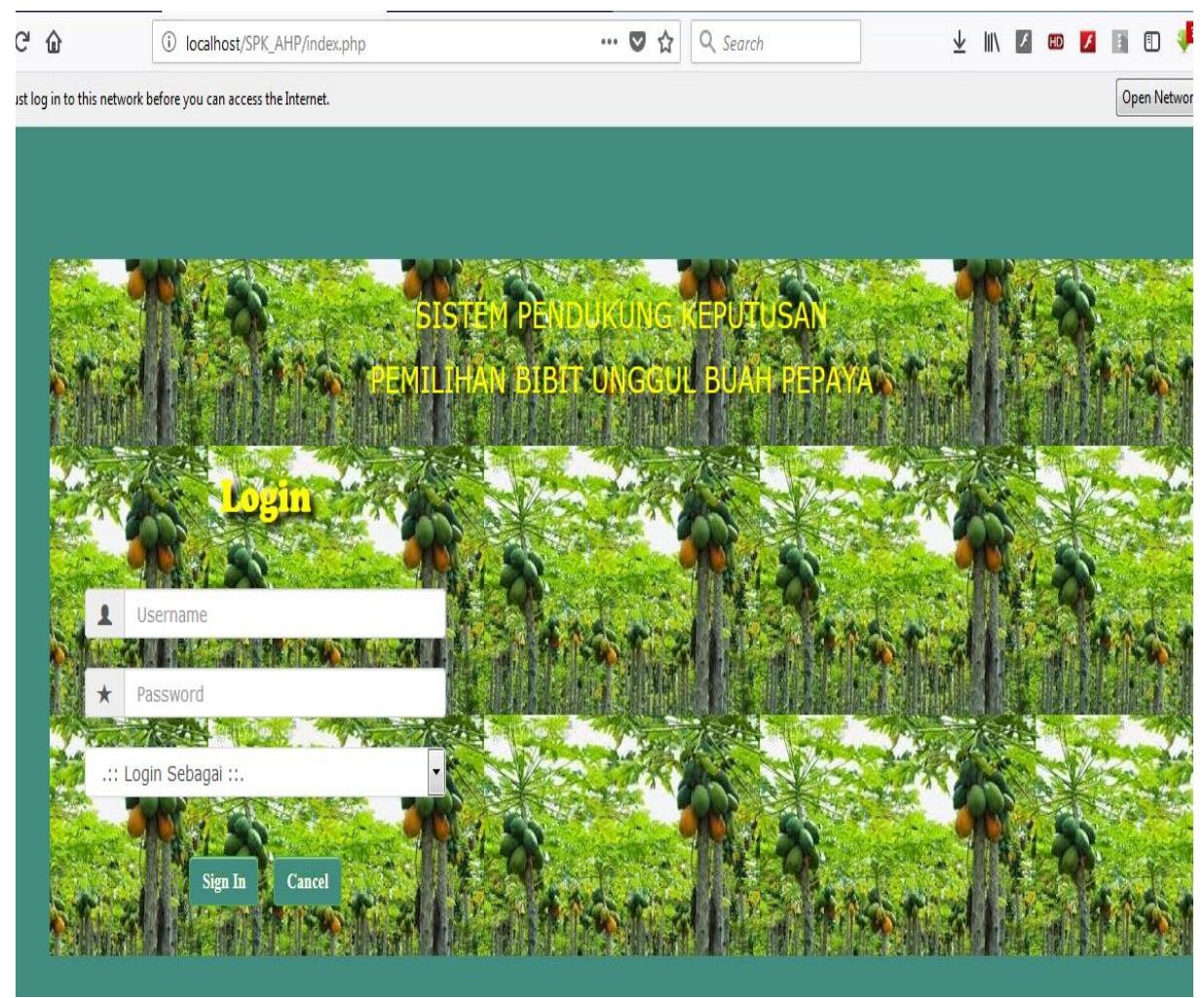

Gambar 4.1 Halaman Awal Website

2. Halaman Index Admin

Halaman index admin merupakan halaman awal yang digunakan administrator setelah login. Halaman ini berisikan keterangan selamat datang kepada administrator.

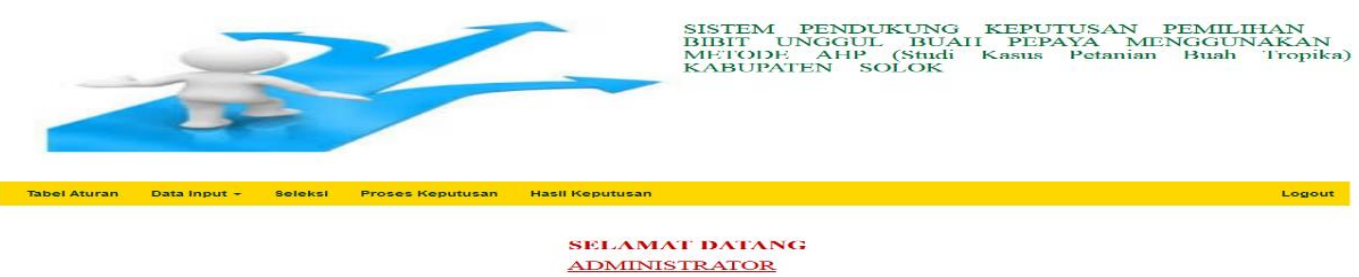

Gambar 4.2 Halaman Index Admin

3. Halaman Panduan

Halaman ini berisikan panduan yang digunakan oleh admin dalam membandingkan kriteria yang satu dengan yang lainnya. 

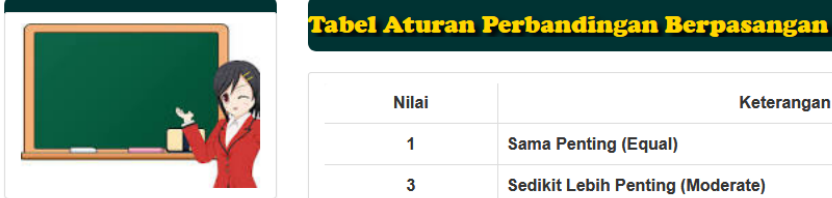

\begin{tabular}{|c|l|}
\hline Nilai & \multicolumn{1}{|c}{ Keterangan } \\
\hline 1 & Sama Penting (Equal) \\
\hline 3 & Sedikit Lebih Penting (Moderate) \\
\hline 5 & Jelas Lebih Penting (Strong) \\
\hline 7 & Sangat Jelas Lebih Penting (Very Strong) \\
\hline 9 & Mutlak Lebih Penting (Extreme) \\
\hline $2,4,6,8$ & Apabila ragu-ragu antara 2 nilai yang berdekatan \\
\hline $1 /(1-9)$ & Kebalikan nilai tingkat kepentingan dari skala 1-9 \\
\hline
\end{tabular}

\section{Gambar 4.3 Halaman Tabel Panduan}

4. Halaman Input Data Varietas

Halaman ini berisikan data tanaman yang akan dimasukan kedalam database oleh admin.

SISTEM PENDUKUNG KEPUTUSAN PEMILIHAN BIBIT UNGGUL BUAH PEPAYA MENGGUNAKAN $\wedge$

Tabel Panduan Data Input - Seleksi Proses Keputusan Hasil Keputusan

\section{Form Input Data Varietas}

\begin{tabular}{l} 
Dapina Agrihorti \\
rrange kemerahan, permukaan kulit halus dan bentuk ujung buah agak lancip \\
Browse... dapina agrihorti.jpg \\
Buah agak lancip (agak slindris) \\
Hijau Keabu-abuari setelah tanam \\
\hline Simpan Reset
\end{tabular}

Gambar 4.4 Halaman Input Data Varietas

5. Halaman Seleksi

Halaman ini berisikan data dari user yang akan dilakukan seleksi. Pada halaman ini terdapat beberapa aturan dan keterangan dari penilaian yang berada pada sisi kiri website. Keterangan ini jugalah nantinya yang akan dijadikan pedoman dalam penilaian. 


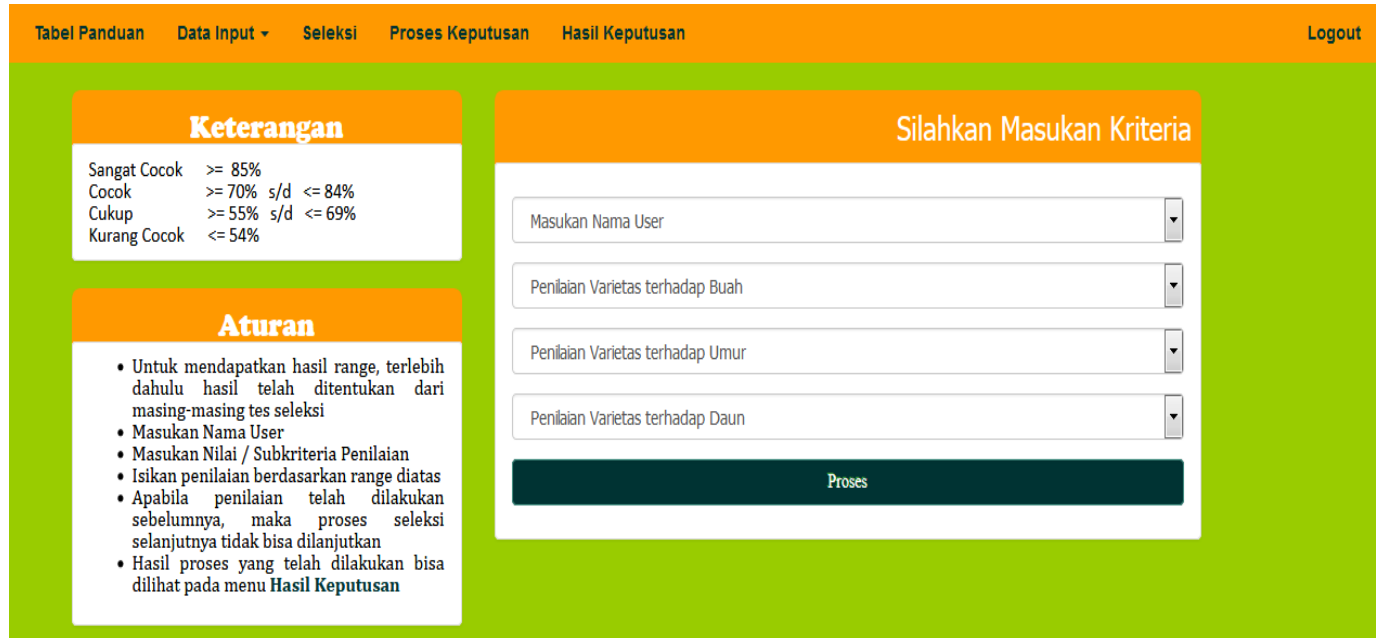

\section{Gambar 4.5 Halaman Seleksi}

6. Halaman Proses Keputusan Matriks Kriteria

Halaman ini berisikan data perbandingan kriteria yang digunakan berupa nilainilai seperti pada halaman panduan yang telah ditampilkan. Nilai inilah yang nantinya akan diproses sesuai dengan rumus perhitungan metode Analytic Hierarchy Process (AHP) yang telah dimasukan kedalam sistem aplikasi.

SISTEM PENDUKUNG KEPUTUSAN PEMILIHAN BIBIT UNGGUL BUAH PEPAYA MENGGUNAKAN

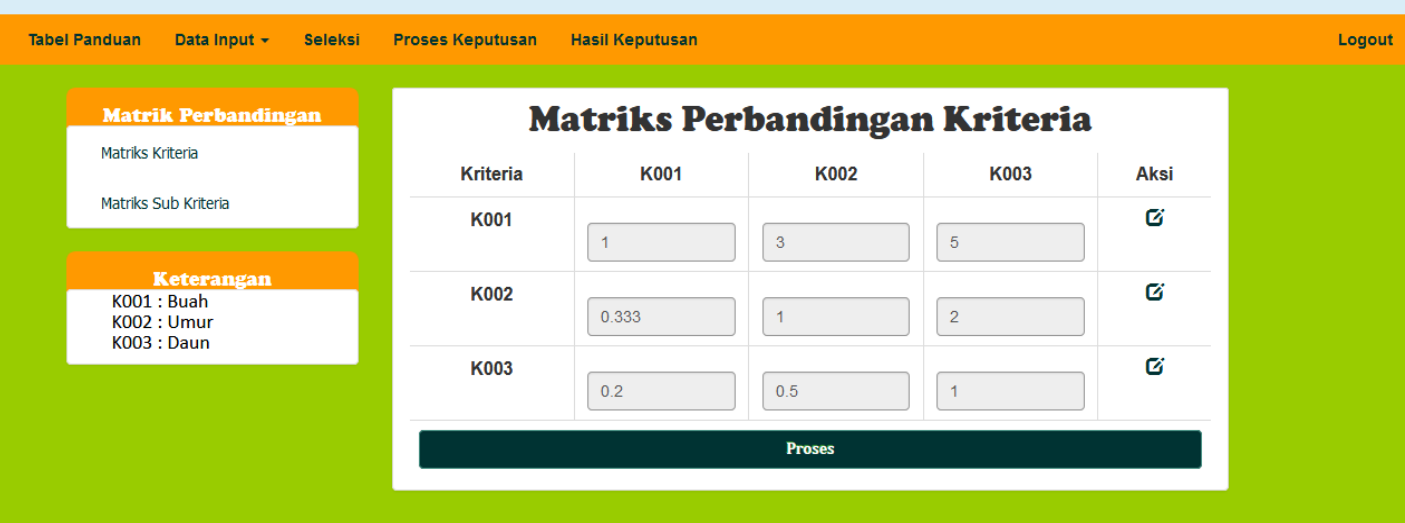

Gambar 4.6 Halaman Proses Keputusan Matriks Kriteria

7. Halaman Proses Keputusan Matriks Subkriteria

Halaman ini berisikan data perbandingan subkriteria yang digunakan berupa nilai-nilai seperti pada halaman panduan yang telah ditampilkan. Nilai inilah yang nantinya akan diproses sesuai dengan rumus perhitungan metode Analytic Hierarchy Process (AHP) yang telah dimasukan kedalam sistem aplikasi. 


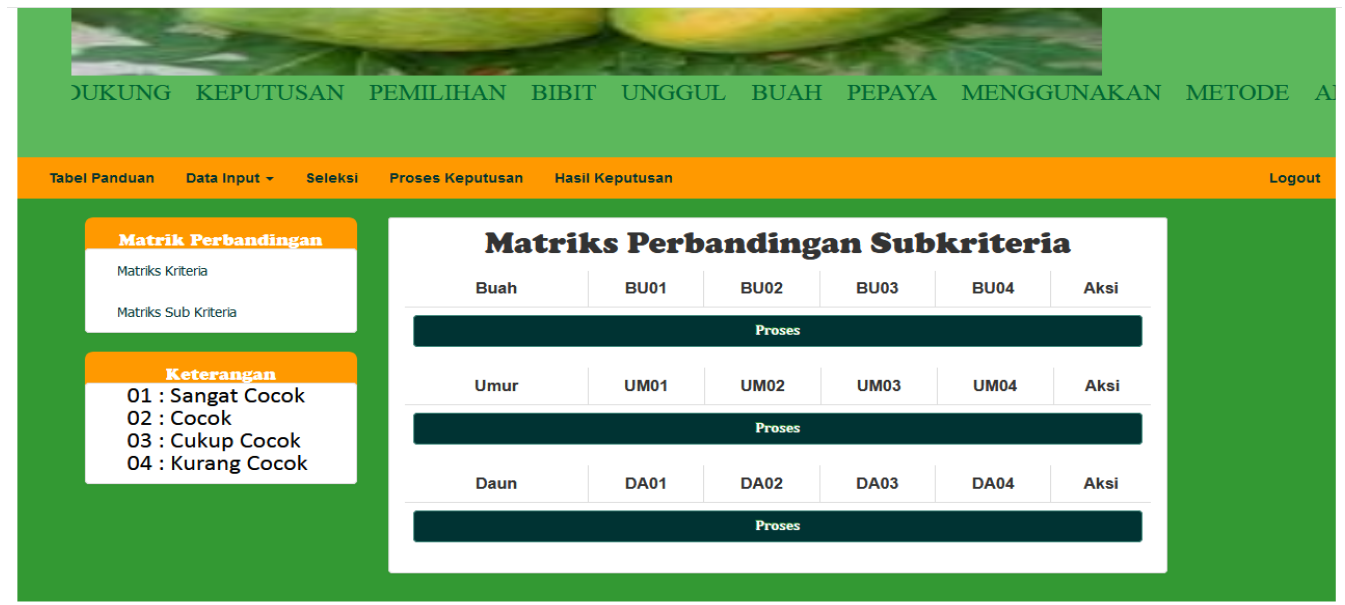

\section{Gambar 4.7 Halaman Proses Keputusan Matriks Subkriteria}

8. Halaman Hasil Keputusan

Halaman ini berisikan hasil dari proses perhitungan yang telah dilakukan oleh administrator dimana terdapat hasil penentuan jenis tanaman pangan apa yang paling cocok untuk ditanam sesuai dengan kriteria dan subkriteria yang telah dicari dan diinputkan oleh user pada halaman sebelumnya.

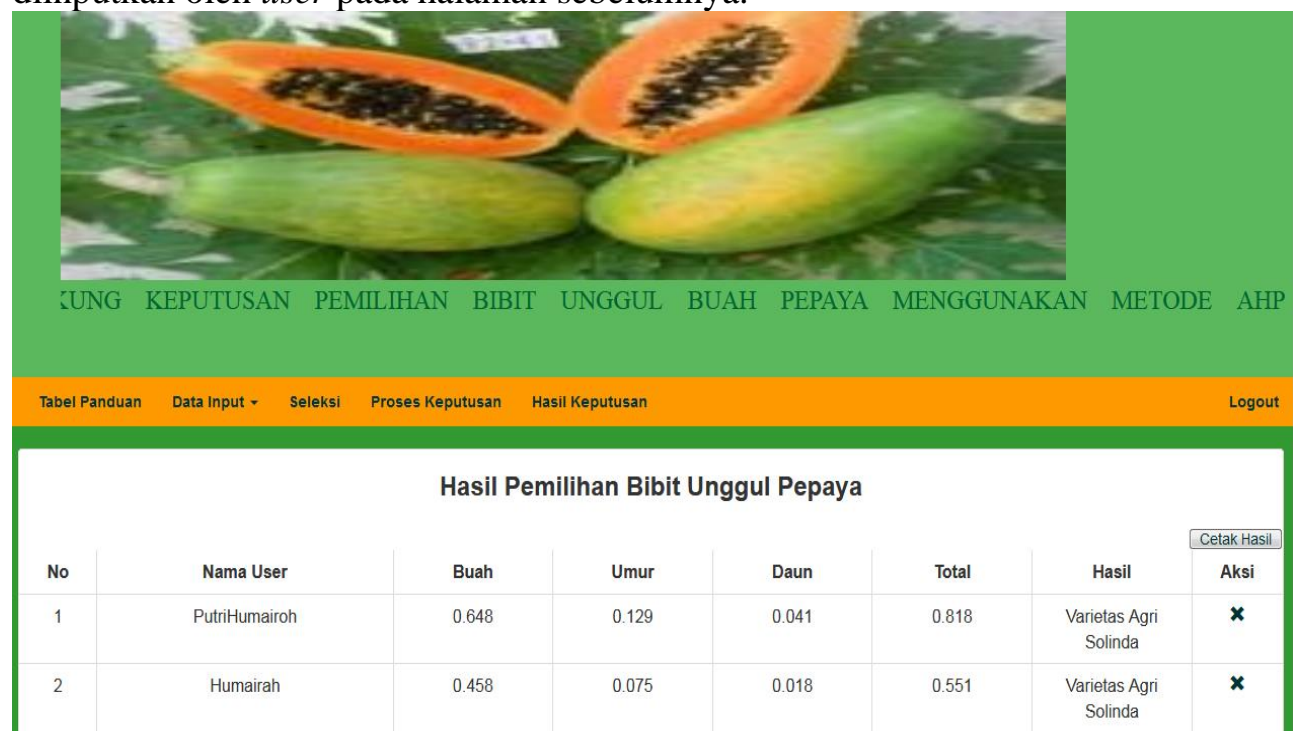

\section{Penutup}

\section{Gambar 4.8 Halaman Hasil Keputusan}

\subsection{Kesimpulan}

Dari deskripsi tentang Pemilihan bibit pepaya unggul Balai Penelitian Buah Tropika Aripan Kab. Solok, sebagaimana telah dikemukakan pada bab-bab sebelumnya dan kemudian dilanjutkan dengan pembahasan masalah, maka dapat ditarik suatu kesimpulan sebagai berikut :

1. Perancangan sistem penunjang keputusan pemilihan bibit pepaya terbaik yang dapat memudahkan pembeli bibit pepaya agar mendapatkan bibit pepaya terbaik dengan perhitungan yang menggunakan metode AHP

2. Sistem Penunjang Keputusan ini dapat membantu memilih bibit pepaya unggul dengan perhitungan data-data yang akurat akan lebih cepat dan aman. 


\subsection{Saran-Saran}

Dari kesimpulan diatas dan penelitian yang dilakukan maka dapat menemukan beberapa saran yang diharapkan dapat menjadi bahan pertimbangan lebih lanjut dalam upaya peningkatan kualitas sistem yang telah dibuat. Adapun saran-saran yang ingin disampaikan adalah :

1. Diharapkan agar sistem ini selalu dilakukan perubahan agar data nya selalu update.

2. Sistem ini dibangun dengan menggunakan bahasa pemrograman php, pada perkembangan selanjutnya, diharapkan aplikasi ini dibangun dengan bahasa pemrograman yang lebih baru sesuai dengan perkembangan zaman.

3. Melakukan pembaruan pada interface dan sistem nya karena seiring berjalannya waktu akan lahir lagi fitur baru yang lebih memanjakan penggunanya.

4.

\section{Referensi}

Fitria, M Zulafan Z. 2011, A Decision Making System To Predict Agribusiness Planting Succesfullness Using Analytic Hierarchy Process Method, Bali.

Setiawan, Bayu Tris. 2017, Sistem Pendukung Keputusan untuk Pemilihan Bibit Unggul Buah Pepaya dengan Metode AHP, Kediri.

Sovia, Rini dan Jimmy Febio. 2011, Membangun Aplikasi E-Library Menggunakan HTML, PHP Script, Dan Mysql Database, Padang.

Situmorang Richard. 2014, Analisis Dan Rekayasa Perangkat Lunak Data Pensiun Pada Dinas Komunikas iInformatika Provinsi Sumatera Utara Dengan Model Waterfall, Medan.

Sulistiyani Sri. 2013, PHP \& MyAdmin, Yogyakarta :Informatika.

S, Rosa A dan M. Shalahuddin. 2013, Rekayasa Perangkat Lunak Terstruktur dan Berorientasi Objek, Bandung : Informatika.

Dermanto, Eko, dkk. 2014. Penerapan Metode Ahp (Analythic Hierarchy Process) Untuk Menentukan Kualitas Gula Tumbu. Jurnal SIMETRIS. Vol. 5 No. 1. ISSN: 2252-4983.

Fazliani, Joan Angelina, dkk. 2017. Sistem Pendukung Keputusan Pemilihan Bibit Unggul Kelapa Sawit dengan Metode Ahp (Analythic Hierarchy Process). Jurnal Prosiding Seminar Ilmu Komputer. Vol. 2 No. 1. ISSN: 2540-7902.

Muhammad, Abulwafa. 2010. Pemilihan Karyawan Berprestasi dengan Metode Ahp (Analythic Hierarchy Process). Jurnal Teknologi Informasi \& Pendidikan. Vol. 1 No. 1. ISSN: 2086-4981.

Jasril, Elin Haerani, dkk. 2011. Sistem Pendukung Keputusan Pemilihan Karyawan Terbaik Menggunakan Metode Fuzzy Ahp (F-AHP). Jurnal Seminar Nasional Aplikasi Teknologi Informasi. ISSN: 1907-5022.

Husein, Muhamad Rendra, Agus Wahyu, dkk. Sistem Pendukung Keputusan Untuk Pemilihan Pananaman Varietas Unggul Pepaya Menggunakan Metode AHP dan Topsis. Jurnal Pengembangan Teknologi Informasi. Vol. 1 No. 10. ISSN: 2548-964X

Nugroho, Adi. 2005. Rational Rose untuk Pemodelan Berorientasi Objek. Bandung: Informatika.

S, Rosa A dan M. Shalahuddin. 2014. Rekayasa Perangkat Lunak Terstruktur dan Berorientasi Objek, Jilid 2. Bandung: Informatika.

Astuti, Yuli, M. Suyanto, dkk. 2012. AHP untuk Pemodelan SPK Pemilihan Sekolah Tinggi Komputer. Jurnal Teknologi Informasi. Vol. VII No. 20. ISSN: 1907-2430. 